\title{
Papers
}

\section{Women's views on the impact of operative delivery in the second stage of labour: qualitative interview study}

\author{
Deirdre J Murphy, Catherine Pope, Julia Frost, Rachel E Liebling
}

\begin{abstract}
Objective To obtain the views of women on the impact of operative delivery in the second stage of labour.

Design Qualitative interview study.

Setting Two urban teaching hospitals in the United Kingdom.

Participants Purposive sample of 27 women who had undergone operative delivery in the second stage of labour between January 2000 and January 2002.

Key themes Preparation for birth, understandings of the indications for operative delivery, and explanation or debriefing after birth.

Results The women felt unprepared for operative delivery and thought that their birth plan or antenatal classes had not catered adequately for this event. They emphasised the importance of maintaining an open mind about the management of labour. They had difficulty understanding the need for operative delivery despite a review by medical and midwifery staff before discharge. Operative delivery had a noticeable impact on women's views about future pregnancy and delivery.

Conclusions Women consider postnatal debriefing and medical review important deficiencies in current care. Those who experienced operative delivery in the second stage of labour would welcome the opportunity to have a later review of their intrapartum care, physical recovery, and management of future pregnancies.
\end{abstract}

\section{Introduction}

Although childbirth is often a joyful time and can have a positive impact on a woman's life and psychological state, it can have a detrimental effect on her emotional wellbeing. Instrumental delivery and caesarean section currently account for around 30\% of all deliveries in British maternity units, with a steady annual increase in rates of caesarean section. ${ }^{1}$ Around 25\%-33\% of women report traumatic symptoms associated with childbirth, and this may be associated with obstetric intervention. ${ }^{2-6}$ Research on understanding women's experience of childbirth has mainly focused on women in general rather than on those who have had high levels of intervention, although recent work has addressed women's experience of caesarean section..$^{7-10}$
Education and preparation for childbirth, including potential complications and interventions, are important parts of antenatal care. When there have been obstetric complications and interventions, methods of reducing emotional morbidity, such as debriefing, have shown conflicting results. ${ }^{11-13}$ Further research is required to understand women's experience of abnormal labour and to establish strategies to minimise psychological morbidity. Women face difficulties of coming to terms with operative delivery and anxieties about future pregnancy and delivery. ${ }^{14}$

We explored women's experience of operative delivery in the second stage of labour. We focus on how prepared women felt for operative delivery, the perceived usefulness of a birth plan, their understanding of why operative delivery was needed, their views on debriefing after delivery, and their preferences for future pregnancy and delivery.

\section{Methods}

We had previously conducted a prospective cohort study of operative delivery in the second stage of labour with 393 women booked for care at two urban hospitals in England who required instrumental vaginal delivery in theatre or caesarean section at full dilation. ${ }^{15}$ The present qualitative study was designed to follow up questions raised by this quantitative work. This incorporated concerns raised by the clinicians, who wanted to understand more about the emotional impact of operative deliveries, and issues raised by the women, who believed that the quantitative approach did not adequately capture their experience. For the qualitative study we selected a subsample of all the women from the cohort who delivered between January 2000 and May 2000 for follow up from semistructured interviews. These women had experienced delivery in the two years before the study and therefore should have been able to recall the event in sufficient detail. To address possible recall problems we sampled a group of women who were not in the original cohort. For this group we contacted all those who had experienced operative delivery between September 2001 and January 2002.

\section{Sample}

Of the 63 women contacted from the original cohort, 31 agreed to be interviewed, 10 declined, and the remaining 22 either did not reply or had changed
Department of Obstetrics and Gynaecology, Maternal and Child Health Sciences, Ninewells Hospital and Medical School, University of Dundee, Dundee DD1 9SY

Deirdre J Murphy professor

Department of Social Medicine, University of Bristol, Bristol BS8 2PR

Catherine Pope lecturer

Julia Frost research assistant

Women's Centre, Southmead Hospital, North Bristol NHS Trust, Bristol BS 10 5NB

Rachel E Liebling specialist registrar

Correspondence to: D J Murphy D.J.Murphy@ dundee.ac.uk

bmj.com 2003;327:1132

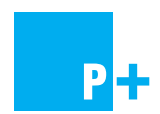

A list of key themes appears on bmj.com 
Characteristics of interviewees and all women experiencing operative delivery during study (1999-2000). Values are numbers (percentages)

\begin{tabular}{|c|c|c|}
\hline Characteristic & Cohort study ( $n=393$ ) & Interviewees $(\mathrm{n}=27)$ \\
\hline Nulliparous & $309(79)$ & $22(81)$ \\
\hline \multicolumn{3}{|l|}{ Maternal age at delivery: } \\
\hline $21-30$ & $204(52)$ & $15(56)$ \\
\hline $31-40$ & $159(41)$ & $11(41)$ \\
\hline Non-white women & $23(6)$ & $1(4)$ \\
\hline \multicolumn{3}{|l|}{ Social class: } \\
\hline | or || & $174(44)$ & $13(48)$ \\
\hline III-VI & $189(48)$ & $14(52)$ \\
\hline Induced labour & $130(33)$ & $7(26)$ \\
\hline Regional anaesthesia & $373(95)$ & $26(96)$ \\
\hline \multicolumn{3}{|l|}{ Hospital of delivery: } \\
\hline Centre 1 & $228(58)$ & $17(63)$ \\
\hline Centre 2 & $165(42)$ & $10(37)$ \\
\hline \multicolumn{3}{|l|}{ Operator experience: } \\
\hline SpR year $\geq 4$ or consultant & $82(21)$ & $9(33)$ \\
\hline Senior house officer or $\mathrm{SpR}$ year 1-3 & $311(79)$ & $18(67)$ \\
\hline \multicolumn{3}{|l|}{ Mode of delivery: } \\
\hline Immediate caesarean & $102(26)$ & $7(26)$ \\
\hline Instrumental & $184(47)$ & $15(52)$ \\
\hline $\begin{array}{l}\text { Caesarean after failed instrumental } \\
\text { delivery }\end{array}$ & $107(27)$ & $5(22)$ \\
\hline \multicolumn{3}{|l|}{ Duration of hospital stay (days): } \\
\hline $0-2$ & $127(32)$ & $10(37)$ \\
\hline$>2$ & $266(68)$ & $17(63)$ \\
\hline Serious maternal morbidity* & $74(19)$ & $4(15)$ \\
\hline Serious neonatal morbidity $\dagger$ & $66(17)$ & $4(15)$ \\
\hline
\end{tabular}

*Includes major obstetric haemorrhage (>1000 ml), third degree perineal tear, and extended uterine incision. tIncludes admission to neonatal intensive care unit, fetal acidosis $(\mathrm{pH}<7.10)$, serious trauma other than facial bruising, and neonatal sepsis.

address. Some of the women were concerned about recall problems, but this was not apparent in the interviews. In the subsample, we identified 50 women who had undergone operative deliveries within the specified period. They received a standardised letter from their obstetrician inviting them to participate. Twelve replied. We did not send out follow up letters to potential participants owing to ethical approval.

Interviews were carried out between March and December 2002. Preliminary analyses and review of the data collection allowed some purposive sampling, which ensured capture of the range of operative delivery experiences (mode of delivery, place of delivery, clinician's experience). We also attempted to include younger women.

\section{Data collection and analysis}

Interviews were arranged at a time and place to suit each woman (generally their own homes), and written consent was obtained. Transcripts of interviews were anonymised, and only the two non-obstetrical members of the research team had access to respondents' names. On request, one respondent received a copy of her transcript. The women were told that they could stop the interview at any time and decline to answer questions without giving a reason. Interviews were conducted in accordance with British Sociological Association guidelines. They lasted between 30 and 120 minutes, and followed a topic guide drafted and piloted by the research team. As data collection progressed, additional items were added as new areas of interest emerged. The interviews were recorded and transcribed verbatim.

The interviews were analysed within an interpretive approach that sought to understand women's experi- ence of delivery and how they made sense of what had happened during the delivery. The authors read all the transcripts. Preliminary ideas and tentative codes were iteratively derived by the researchers, who met to discuss, elaborate, and agree on the emerging themes. Two authors (JF and CP) developed these ideas into a set of thematic headings and subcodes that were used as the basis for thematic coding using ATLAS.ti software. ${ }^{16}$ This software was developed for grounded theory approaches to data analysis, but we used it primarily to manage the dataset and to allow systematic searching and cross referencing. By comparing transcripts and exploring negative cases at subsequent readings and meetings, we were able to develop themes and to confirm that all themes had been explored. The themes we present are those that we believe are of most interest to a clinical and health services research audience; some of the more sociological analysis was presented elsewhere (J Frost, C Pope, D Murphy, R Liebling, 34th annual conference of the British Sociological Association Medical Sociology Group, University of York, 2002). The interviews we present here are representative of the key themes, reflect the range of accounts, and show contrasting views.

\section{Results}

Overall, 43 women agreed to be interviewed, and of these, 27 participated. Interviewees were generally representative of the earlier cohort (table). All the interviewees had attended for routine antenatal care, and all had attended antenatal classes except two younger women. Twenty six women stated that they had planned for a "natural" delivery before labour, and one stated that she had wanted a caesarean section. Few women experienced obstetric complications before delivery, although one woman developed pre-eclampsia. Most women underwent regional anaesthesia for delivery, and this was unlikely to have affected their recall of events. None of the women described either the diagnosis or the treatment of postnatal depression, perhaps because such women are less willing to be interviewed. Although some women were concerned about recalling events in detail, we obtained in-depth information from all the interviewees. The women were generally satisfied with the support and explanations they received in labour and during delivery but identified deficiencies in antenatal and postnatal care (see bmj.com).

Preparation for delivery and usefulness of birth plan Many women expressed reservations about preparation for delivery and the usefulness of their birth plan (box 1). For some, operative delivery was not contemplated or had not been considered a relevant component of antenatal education in their classes. A gap was apparent in information relating to instrumental delivery. Some women described their birth plan as meaningless and thought that nothing they had hoped for had been achieved. Others described the uncontrollable nature of events and believed that they could not have planned for this. They noted the importance of maintaining an open mind and taking advice as it proved necessary. Several patients expressed concern that the emotional impact of operative delivery had not been considered as part of antenatal preparation. 
Box 1: Preparation for delivery and usefulness of birth plan

"I didn't even read the chapter in the book, it just wasn't going to happen." Interviewee 2, aged 40 (caesarean section)

"I didn't feel as though I had prepared myself for the possibility of a caesarean." Interviewee 10, aged 39 (ventouse and caesarean section)

"I sort of missed out the forceps and ventouse, in my mind I'd sort of thought it was going to be a natural delivery or caesarean, so I hadn't really considered forceps or ventouse." Interviewee 23, aged 39 (ventouse)

“... birth plan, my birth nightmare, after months of preparation it just went out of the window." Interviewee 3 , aged 38 (caesarean section)

"Nothing in my birth plan actually happened in the birth at all ... What a joke! I'll never make one again." Interviewee 22, aged 31 (forceps and caesarean section)

"I don't know whether antenatal classes would have helped because you couldn't plan what was going to happen." Interviewee 12, aged 33 (ventouse and forceps)

"I did realise that there would be certain circumstances beyond my control, and I would take what advice was given at the time." Interviewee 8, aged 34 (forceps) "I just said to me midwife: I'll go with the flow, you know ... I was quite happy to go in and have a normal birth, and no pain relief, if I didn't have to have any, and if I did ..." Interviewee 17, aged 38 (caesarean section)

"The emotional impact of the caesarean just wasn't dealt with anywhere." Interviewee 3, aged 38 (caesarean section)

Understanding of indications for operative delivery Many of the women expressed difficulty in fully understanding why they had needed an operative delivery; typically they suggested that either they or the baby had failed to achieve normal delivery (box 2). The indications related to the size of the baby, fetal position, and concern about fetal compromise, but few women were clear about the precise reason for operative delivery. Few women with babies showing signs of fetal distress recognised that there was concern about the baby. Most women did not differentiate between immediate caesarean section and caesarean section after failed attempt at instrumental delivery. This observation persisted even when there was trauma to the baby. The one notable exception was a woman who thought that forceps delivery had been attempted despite her expressed preference for immediate caesarean section or a brief attempt at ventouse delivery.

\section{Need for debriefing and medical review}

None of the women remembered a clear discussion of the indication for, or method of, intervention and implications for the future despite both midwifery and medical review in the postnatal period (box 3). This ranged from not remembering any contact to little recollection of the content of discussion postnatally. The wish for an in-depth explanation of the delivery events was expressed frequently. Most women believed that it should be when they had recovered from the initial trauma of childbirth and motherhood.

\section{Future pregnancy and delivery}

Many women described ongoing anxieties about future pregnancies (box 4). In some cases this was sufficient to deter them from having further children, although they had planned for a large family. For those who were prepared to contemplate a further pregnancy, the preferred mode of delivery varied. Despite anxiety, many women still preferred to try for a natural labour in a future pregnancy and hoped that it would go according to their plan. One woman thought that a future operative delivery would be less worrying: others were sure that they would opt for caesarean section.

\section{Discussion}

Women who have undergone an operative delivery in the second stage of labour report deficiencies in antenatal preparation, unrealistic birth plans, a limited understanding of the indication for the delivery, and insufficient opportunity for detailed postnatal review. Operative delivery has a noticeable impact on women's views about future pregnancies and preferred mode of future delivery.

Antenatal preparation for childbirth aims to build women's confidence in their ability to give birth and to care for their babies. ${ }^{17} \mathrm{~A}$ third of women in British maternity units undergo operative delivery, and our study suggests that their educational needs may not be adequately met. The birth plan was heralded as an opportunity for women to indicate their wishes during labour. ${ }^{18}$ This planning does not, however, address the issue of instrumental delivery, and this limits women's ability to make informed decisions. It has been suggested that obstetric input to the antenatal care of women with normal pregnancies offers little or no clinical benefit or benefit for the consumer. ${ }^{19}$ This has

\section{Box 2: Understanding of indications for operative delivery}

"I couldn't do it for myself. I still don't know why." Interviewee 3, aged 37 (ventouse and forceps)

"Her head was tilted back apparently so that was why she couldn't push her way out." Interviewee 4, aged 21 (caesarean section)

"He was quite big, he had a big head." Interviewee 15, aged 26 (ventouse and forceps)

"He tried to do sort of front crawl, while he was doing it, and his hand came out before his head." Interviewee 2 , aged 40 (caesarean section)

"I had an extra flap of skin on my cervix, something was getting in the way, every time that she was coming through, and I had quite a narrow pelvis ..." Interviewee 18, aged 30 (ventouse and forceps)

"She said that he wouldn't go round the last u-bend, if that means anything to you?" Interviewee 16, aged 32 (ventouse and caesarean section)

"She was going into distress. It was either get her out or lose her." Interviewee 7, aged 33 (caesarean section) "At one point, before I went to theatre I had something put inside me to test his blood off the top of his head and the result of that [abnormal result of fetal blood sample] made me go down to theatre." Interviewee 12, aged 33 (ventouse and forceps) 
meant that many women meet an obstetrician for the first time in the second stage of labour, with little understanding of the potential choices available for management. Although most pregnant women continue to aim for spontaneous vaginal delivery, it is important that they are aware of the possibility of operative intervention and what that entails. This requires a review of current antenatal education and the respective roles of caregivers.

Changing Childbirth emphasised the importance of women's participation in decision making about pregnancy and childbirth. ${ }^{20}$ The women in our study showed a limited understanding of the indication for operative delivery and implications for the future. This finding is mirrored in a Scottish study where women felt significantly less satisfied with the information they received and their involvement in the decision making process after emergency caesarean section compared with elective caesarean section. ${ }^{21}$ Shortcomings in postnatal review were not expressed in the immediate postnatal period-when women have greatest access to caregivers-but emerged after discharge. Debriefing has been advocated as a strategy to minimise the trauma of childbirth, but to date it has had disappointing results. A randomised controlled trial of a midwife led debriefing session in hospital among women who had undergone operative deliveries was ineffective in reducing depression six months after birth. ${ }^{12}$ Similarly, additional home visits by support workers in the postnatal period conferred no health benefit over traditional community midwifery for women experiencing all types of delivery. ${ }^{11}$ Further research is required to understand the optimal timing, venue, and type of healthcare professional for postnatal review after operative delivery.

\section{Box 3: Need for debriefing and further review}

"The consultants come round but they never actually came and seen me." Interviewee 7, aged 33 (caesarean section)

"I don't remember anyone coming and saying "look this is what happened' or why we did it, or anything." Interviewee 13, aged 37 (ventouse and forceps)

"I remember the doctor coming up and seeing me ... I had contact but I couldn't tell you what it was about." Interviewee 9, aged 27 (forceps)

"The doctor did go to my husband and talk to him. He said it was like she was not explaining but justifying what she did." Interviewee 2, aged 40 (caesarean section)

"I'd have liked to have sat down and talked it through, but, yes there are things that are left unanswered ..." Interviewee 22, aged 31 (forceps and caesarean section)

"I think talking to me a little bit afterwards maybe at three or four months would have been nicer, when I'd got over having a new baby." Interviewee 14, aged 32 (forceps and caesarean section)

"It is major surgery and you don't really get the follow up. You're just left unless you have complications. I'd like to go to the hospital for a more detailed check, you need to see someone connected with surgery." Interviewee 10, aged 39 ventouse and caesarean section)

\section{Box 4: Future pregnancy and delivery}

"A lot of women after a year just jump straight in and think 'oh well another one straight away,' but I was totally, I was totally put off." Interviewee 1, aged 23 (forceps and ventouse)

"I would like another baby but that is there at the back of my mind thinking oh could I really go through all that again." Interviewee 12, aged 32 (ventouse and forceps)

"I'd like it to go the way that I want it to next time, now I know how it can go." Interviewee 3, aged 38 (caesarean section)

"I do feel that I've cheated a bit, I do feel as though maybe I would have liked to have felt a bit more ... I would have liked to have been a bit more in control ... erm ... yeah, a bit more of a normal delivery, I would like next time." Interviewee 20, aged 31 (ventouse and forceps)

"If I have to have that with another baby it won't ever be as worrying because I know exactly what to expect." Interviewee 9, aged 29 (forceps)

"I don't want to have to go through all of that again ... I just wanna have one slice in the belly and whoosh!" Interviewee 13, aged 37 (ventouse and forceps)

"I'd rather have a caesarean than go through another instrumental delivery." Interview 18, aged 30 (ventouse and forceps)

The physical and psychological outcome of an operative delivery has important implications for future pregnancies and mode of delivery. A quantitative follow up of our original cohort showed that nearly $70 \%$ of women who had had an instrumental delivery in theatre and $40 \%$ who had had a caesarean section at full dilation would still prefer to aim for vaginal delivery in a future pregnancy. ${ }^{14}$ This finding is reflected in the views expressed in our study. Many women still preferred natural childbirth despite the inherent uncertainties of labour. These views are important as there is growing evidence that maternal choice is being limited by obstetric concerns about the risk of uterine rupture, with some North American maternity units declining access to vaginal birth after caesarean section. ${ }^{22}$

Our sample size, typical of qualitative research, was small, and the results are not generalisable to wider populations in a statistical sense. The accounts presented here do not reflect all mothers' experiences. These women may have been self selected-that is, these women may have been more prepared to tell their stories. The women we interviewed were broadly representative of those undergoing operative delivery in the region, although some caution is needed when translating these findings to non-white and younger populations. On first review the women seemed to be older than the average age for giving birth, but operative delivery is associated with higher maternal age and it had been two years since the women delivered. ${ }^{23}$ The detailed accounts indicate that recall was not as problematic as we had anticipated. The analysis was undertaken by a multidisciplinary team of sociologists and obstetricians to ensure that categories and themes were robust and that agreement was reached. The sampling and analysis also achieved data saturationthat is, no new themes emerged and all segments of the 


\section{What is already known on this topic}

An increasing proportion of women who aim for spontaneous vaginal delivery undergo operative delivery in the second stage of labour

Up to a third of women report traumatic symptoms associated with childbirth, which can be exacerbated by obstetric intervention

\section{What this study adds}

Current antenatal preparation for labour and delivery does not adequately address operative intervention

Operative delivery has a noticeable impact on women's preferences for future deliveries

Women who have undergone operative delivery would value a later review of their intrapartum care, recovery, and management of future pregnancies

data were accounted for. The convergence of the ideas presented here with other research suggests that our results are transferable to other similar populations. ${ }^{21}{ }^{22}$

\section{Conclusions}

It is essential that women are listened to if progress is to made in the provision of safe and acceptable intrapartum care. The priority for the obstetrician is safe delivery for mother and baby, and to a large extent this is achieved. Maternal satisfaction with the birth experience must now be addressed, even within the context of adverse clinical events. Improvements in antenatal preparation for delivery, a realistic approach to the birth plan, and effective postnatal review are good places to start.

We thank the women who participated, Lisa Verity, Rebecca Swingler, and Roshni Patel for recruiting the women and collecting early morbidity data, and Karen Goyder for midwifery advice.

Contributors: DJM, CP, and REL designed the study. JF performed the interviews and prepared the transcripts. All authors contributed to the analysis and interpretation of the transcripts. JF and CP developed the thematic headings and coding. DJM wrote the report, with help from the other authors; she will act as guarantor for the paper.

Funding: JF was funded by South and West research and development. The guarantor accepts full responsibility for the conduct of the study, had access to the data, and controlled the decision to publish.

Competing interests: The authors have personally experienced a range of deliveries varying from home birth to Kiellands rotational forceps delivery.

Ethical approval: Research ethics approval was obtained for contacting women from both time periods.

1 Thomas J, Paranjothy S. National sentinel caesarean section audit report. Royal College of Obstetricians and Gynaecologists Clinical Effectiveness Support Unit, London: RCOG Press, 2001. Support Unit, London: RCOG Press, 2001

2 Czarnocka J, Slade P. Prevalence and predictors of post-traumatic stress symptoms following childbirth. Br J Clin Psychol 2000;39:35-51.

3 Creedy DK, Shochnet IM, Horsfall J. Childbirth and the development of acute trauma symptoms: incidence and contributing factors. Birth 2000;27:104-11.

4 Wijma K, Soderquist J, Wijma B. Post-traumatic stress disorder after childbirth: a cross sectional study. J Anxiety Disord 1997;11:587-97.

5 Menage J. Post-traumatic stress disorder after childbirth: the phenomenon of traumatic birth. CMAJ 1997;156:831-5.

6 Fisher J, Astbury J, Smith A. Adverse psychological impact of operative obstetric interventions: a prospective longitudinal study. Aust NZ J obstetric interventions: a
Psychiatry 1997;31:728-38.

7 Mackey MC. Women's evaluation of the labour and delivery experience. Nursing Connections 1998;11:19-32.

8 DiMatteo MR, Kahn KL, Berry SH. Narratives of birth and the postpartum: analysis of the focus group responses of new mothers. Birth 1993;20:204-11.

9 Statham H, Weaver J, Richards M. Why choose caesarean section? Lancet 2001;357:635. 10 Weaver J. Talking about caesarean section. MIDIRS Midwifery Digest
2000;10:487-90.

11 Morrell CJ, Spilby H, Stewart P, Walters S, Morgan A. Costs and effectiveness of community postnatal support workers: randomised controlled trial. $B M J$ 2000;321:593-7.

12 Small R, Lumley J, Donohue L, Potter A, Waldenstrom U. Randomised controlled trial of midwife led debriefing to reduce maternal depression after operative childbirth. BMJ 2000;321:1043-7.

13 Lavender T, Walkinshaw SA. Can midwives reduce postpartum psychological morbidity? A randomised trial. Birth 1998;25:215-21.

14 Murphy DJ, Liebling RE. Cohort study of maternal views on future mode of delivery following operative delivery in the second stage of labor. $\mathrm{AmJ}$ Obstet Gynecol 2003;188:542-8.

15 Murphy DJ, Liebling RE, Verity L, Swingler R, Patel R. Cohort study of the early maternal and neonatal morbidity associated with operative delivery in the second stage of labour. Lancet 2001;358:1203-7.

16 Muhr T. ATLAS/ti for windows. Berlin: Scientific Software Development, 1997.

17 Nolan ML, Hicks C. Aims, processes and problems of antenatal education as identified by three groups of childbirth teachers. Midwifery 1997;13:179-88

18 Ekeocha CE, Jackson P. The "birth plan" experience. Br J Obstet Gynaecol 1985;92:97-101.

19 Tucker JS, Hall MH, Howie PW, Reid ME, Barbour RS, Florey CduV, Mcllwaine M. Should obstetricians see women with normal pregnancies? A multicentre randomised controlled trial of routine antenatal care by general practitioners and midwives compared with shared care led by obstetricians. $B M J$ 1996;312:554-9.

20 Department of Health. Changing childbirth. Part 1: Report of the expert maternity group. London, DoH: HMSO, 1993 .

21 Graham WJ, Hundley V, McCheyne AL, Hall MH, Gurney E, Milne J. An Graham WJ, Hundley V, McCheyne AL, Hall MH, Gurney E, Milne J. An
investigation of women's involvement in the decision to deliver by caesarean section. BrJ Obstetr Gynaecol 1999;106(3):213-20.

22 Maternity Center Association. Listening to mothers:report of the first national US survey of women's childbearing experiences. Executive summary and recommendations issued by the Maternity Center Association. New York: Maternity Center Association, 2002.

23 Main DM, Main EK, Moore DH 2nd. The relationship between maternal age and uterine dysfunction: a continuous effect throughout reproductive life. Am J Obstet Gynecol 2000;182:1312-20.

(Accepted 18 August 2003) 